\title{
Repeated Intraperitoneal Administration of Low-Concentration Methylcellulose Leads to Systemic Histologic Lesions Without Loss of Preclinical Phenotype
}

\author{
Stacey Meeker, Megan Beckman, Kevin M. Knox, Piper M. Treuting, \\ and (D) Melissa Barker-Haliski \\ Department of Comparative Medicine, School of Medicine (S.M., P.M.T.), Department of Biology, College of Arts and Sciences \\ (M.B.), and Department of Pharmacy, School of Pharmacy (M.B., K.M.K., M.B.-H.), University of Washington, Seattle, \\ Washington
}

Received February 10, 2019; accepted July 31, 2019

\begin{abstract}
Methylcellulose (MC; $0.5 \%$ concentration) is commonly used when evaluating investigational agents for efficacy in preclinical models of disease. When administered by the oral $(\mathrm{PO})$ route, $\mathrm{MC}$ is considered a Food and Drug Administration "generally recognized as safe" compound. Yet, there is limited data pertaining to the tolerability and impact on model fidelity of repeated intraperitoneal administration of $0.5 \% \mathrm{MC}$. Chronic administration of high-concentration $\mathrm{MC}(2 \%-2.5 \%)$ has been used to induce anemia, splenomegaly, and lesions in multiple organ systems in several preclinical species. Histopathological findings from a diagnostic pathologic analysis of a single mouse from our laboratory with experimentally induced chronic seizures that had received repeated intraperitoneal administration of antiseizure drugs delivered in $\mathrm{MC}$ revealed similar widespread lesions. This study thus tested the hypothesis that chronic administration of intraperitoneal, but not PO, MC incites histologic lesions without effects on preclinical phenotype. Male CF-1 mice ( $n=2-14$ /group) were randomized to receive either 6 weeks of twice weekly $0.5 \% \mathrm{MC}$ or saline (intraperitoneal or PO) following induction of chronic seizures.
\end{abstract}

Histology of a subset of mice revealed lesions in kidney, liver, mediastinal lymph nodes, mesentery, aorta, and choroid plexus only in intraperitoneal MC-treated mice $(n=7 / 7)$. Kindled mice that received $\mathrm{MC} \mathrm{PO}(n=5)$ or saline (intraperitoneal $n=6, \mathrm{PO}$ $n=3$ ) had no lesions. There were no effects of intraperitoneal MC treatment on body weight, appearance, seizure stability, or behavior. Nonetheless, our findings suggest that repeated intraperitoneal, but not $\mathrm{PO}, \mathrm{MC}$ elicits systemic organ damage without impacting the model phenotype, which may confound interpretation of investigational drug-induced histologic lesions.

\section{SIGNIFICANCE STATEMENT}

Methylcellulose ( $0.5 \%$ concentration) is commonly used when evaluating investigational agents for efficacy in preclinical models of disease. Herein, we demonstrate that repeated administration of $0.5 \%$ methylcellulose by the intraperitoneal, but not oral, route results in systemic inflammation and presence of foam-laden macrophages but does not impact the behavioral phenotype of a rodent model of neurological disease.

\section{Introduction}

Methylcellulose (MC) is a commonly used vehicle for the delivery of investigational agents in preclinical studies. Lowconcentration $\mathrm{MC}(0.5 \%)$ is widely used to formulate many investigational agents in preclinical animal models, including antitumor agents (Ehteda et al., 2012), antiseizure drugs (ASDs) (Barton et al., 2001; Rowley and White, 2010; Srivastava and White, 2013; Koneval et al., 2018), analgesics (Smith et al., 2017), and antinociceptive agents (G et al., 2014). Within drug-development laboratories wherein a chronic disorder is being modeled (e.g., epilepsy), animals can be serially reused

This work was supported by the University of Washington Departments of Comparative Medicine and Pharmacy.

Laboratory of Origin: M.B.-H., Department of Pharmacy, University of Washington.

https://doi.org/10.1124/jpet.119.257261. for drug screening of multiple investigational agents delivered via intraperitoneal or oral (PO) administration in lowconcentration $\mathrm{MC}$ to minimize animal numbers (Srivastava and White, 2013; Koneval et al., 2018). MC is a generallyrecognized-as-safe compound as defined by the Food and Drug Administration when administered by the oral route, which has further supported the preference of this vehicle for acute and chronic investigational drug administration studies, including within the numerous preclinical seizure and epilepsy models of the National Institute of Neurological Disorders and Stroke Epilepsy Therapy Screening Program (Kehne et al., 2017).

Although frequently used, limited data exist pertaining to the safety, tolerability, and impact on the preclinical model phenotype of repeated systemic administration of lowconcentration MC in laboratory animals. Chronic oral administration of escalating concentrations of $\mathrm{MC}(0 \%-25 \%)$

ABBREVIATIONS: ASD, antiseizure drug; CKM, corneal-kindled mouse; CNS, central nervous system; FC, foam cell; MC, methylcellulose; OF, open field; PAS, periodic acid-Schiff; PO, oral (per os); SAL, saline. 
in chow is well tolerated in rats, rabbits, and dogs, with concentrations up to $5 \%$ having no impact on growth after over 1 year of chronic administration (Hodge et al., 1950). However, long-duration ( 4 weeks or more) chronic administration of highconcentration $\mathrm{MC}(2 \%-2.5 \%)$ delivered by the intraperitoneal route has historically been used to induce anemia and splenomegaly in rats and dogs (Teoh, 1961; Weissman et al., 1961). Further, these studies have reported the accumulation of foamladen macrophages in the glomerular capillaries, liver, spleen, lymph nodes, and other tissues in rodents administered MC via intraperitoneal and intravenous routes with both acute (single dose) and chronic ( $1 \times /$ day for 4-12 weeks) drug administration regimens as assessed by diagnostic histopathology (Weissman et al., 1961; Roth and Krinke, 1994; Kaneko et al., 2003). Similarly, diagnostic necropsy and histopathology of a single corneal-kindled mouse (CKM), a well established moderatethroughput preclinical model of chronic temporal lobe epilepsy, in use within our laboratory for the repeated evaluation of investigational ASDs formulated in low-concentration MC, similarly demonstrated these foam-laden cells within the glomeruli, liver, spleen, lymph nodes, mesentery, serosal surfaces, and pancreas with widespread attending inflammation. Rodents with chronic seizures exhibit greater sensitivity to chemical compounds compared with naïve rodents, including reduced threshold for motor-impairing adverse effects (Honack and Loscher, 1995; Potschka and Loscher, 1999; Klitgaard et al., 2002); thus, it was unclear if these histologic lesions were limited to kindled rodents as a result of their increased sensitivity to adverse drug effects or a more broad effect of low-concentration MC in mice in general. We thus endeavored to define whether repeated administration of low-concentration MC delivered via the intraperitoneal versus $\mathrm{PO}$ route induced histologic lesions in epileptic and/or nonepileptic mice and sought to determine if repeated administration of low-concentration MC is associated with any loss of model fidelity in CKM versus shamkindled mice.

This study was designed to evaluate the systemic and behavioral impact of repeated administration of $\mathrm{MC}$ at a concentration $(0.5 \%)$ most commonly used for early evaluations of investigational drugs for many clinical disorders, including epilepsy, cancer, and neuropathic pain (Ehteda et al., 2012; G et al., 2014; White and Barker-Haliski, 2016; Smith et al., 2017; Patra et al., 2019), and determine whether low-concentration MC itself incites systemic lesions that could affect our ability to adequately assess novel ASDs or other investigational agents. Finally, because epilepsy itself is associated with increased central neuroinflammation (Vezzani et al., 2013; Barker-Haliski et al., 2017b), and peripheral inflammation may also exacerbate seizure severity or accelerate epileptogenesis (Auvin et al., 2010a,b; Cusick et al., 2013), any induction of systemic inflammation may alter the disease pathogenesis in our CKM model, which may further modify the preclinical model phenotype. For example, the kindled seizure stability could be affected or chronic behavioral deficits exacerbated as a result of the enhanced peripheral inflammation induced by chronic MC administration (Auvin et al., 2010b). This study highlights the necessity of considering and evaluating the behavioral and systemic effects of repeated and/or chronic administration of diluents and vehicles used in preclinical drug studies.

\section{Materials and Methods}

Mice. Three-week-old, male Hsd:NSA (CF-1) mice were obtained from a commercial vendor (12-14 g; Envigo, Haslett, MI). Animals were housed on a 14:10 light:dark cycle within the University of Washington animal care facilities. Animals were given free access to food (Irradiated PicoLab Rodent Diet 5053; LabDiet, St. Louis, MO) and water (reverse osmosis purified, chlorinated, water provided in hydropacs or as automatic rack water), except during the periods of behavioral manipulation. Animals were initially housed five per cage in autoclaved individually ventilated cages (Allentown Inc., Allentown, NJ) with autoclaved corn cob bedding (The Andersons, Maumee, $\mathrm{OH}$ ) and free access to nesting materials (Nestlets; Ancare, Bellmore, NY). Mice were maintained specific-pathogen free via a rodent healthmonitoring program and were certified by the vendor to be free of specific rodent pathogens, including ectoparasites, endoparasites, enteric protozoan, Encephalitozoon cuniculi, ectromelia virus, Hantaan virus, $\mathrm{K}$ virus, lactic dehydrogenase-elevating virus, minute virus of mice, mouse adenovirus, mouse cytomegalovirus, mouse hepatitis virus, mouse parvovirus, mouse polyoma virus, mouse rotavirus, mouse thymic virus, murine norovirus, pneumonia virus of mice, respiratory enteric virus III, sendai virus, Theiler's murine encephalomyelitis virus, Helicobacter spp., as well as known enteric and respiratory bacterial pathogens. All procedures were approved by the University of Washington Institutional Animal Care and Use Committee and conformed to the Animal Research: Reporting of In Vivo Experiments guidelines (Kilkenny et al., 2011).

Corneal Kindling. Following a 1- to 2-week acclimation period, mice underwent corneal kindling $(n=47)$ or sham kindling $(n=35)$ for 3 to 4 weeks, consistent with our established protocols (Barker-Haliski et al., 2017a; Koneval et al., 2018). Corneal-kindled mice received a 3 -second $(60 \mathrm{~Hz}, 3-\mathrm{mA}$ intensity) stimulation twice daily until acquisition of kindling criterion defined as five consecutive Racine stage 5 seizures. Each twice-daily corneal stimulation was delivered at least 4 hours apart. Sham-kindled mice received twice-daily handling, topical tetracaine, and electrode application without electrical stimulation. Kindling criterion was reached after twice-daily corneal stimulation for 10-16 days. Any mouse not achieving the fully kindled state was not included in this study.

Influenza Clinical Control. A cohort of 9-week-old, female, C57BL/6J mice $(n=10)$ was obtained from Jackson Laboratories (Bar Harbor, ME) to serve as a positive control for the clinical examination scoring criteria. Mice were allowed to acclimate to the housing facility for 1 week. Following acclimation, mice were lightly anesthetized with isoflurane gas and infected via oropharyngeal aspiration with $50 \mu \mathrm{l}$ of influenza A/Puerto Rico/8/34 virus diluted in $1 \times$ phosphate-buffered solution to 0.5 times the $\mathrm{LD}_{50}$ (10 plaque-forming units). Mice were scored using the previously described visual clinical disease scoring criteria 8 days post inoculation during the peak disease period. No tissues were collected, nor were behavioral assessments performed for this cohort.

MC or Saline Administration Paradigm. MC (0.5\%; catalog number M0430; Sigma-Aldrich) was formulated in sterile water and administered intraperitoneally or $\mathrm{PO}$ at a volume of $0.01 \mathrm{ml} / \mathrm{g}$, twice/ week for 6 weeks upon acquisition of the fully kindled state. Sterile saline (SAL) was similarly administered $(0.01 \mathrm{ml} / \mathrm{g})$. Administration of $0.5 \% \mathrm{MC}$ or SAL twice/week for 6 weeks commenced 5-7 days after the last stimulation (or sham) needed for all mice to be fully kindled. CKM were randomized to receive either $0.5 \% \mathrm{MC}$ or SAL by the intraperitoneal (MC: $n=14$; SAL: $n=12$ ) or PO (MC: $n=5$; SAL: $n=3$ ) route. Sham-kindled mice were similarly randomized to receive either MC or SAL by the intraperitoneal (MC: $n=13$; SAL: $n=12$ ) or PO (MC: $n=5$; SAL: $n=5$ ) route. CKM were randomized into SAL or MC treatment groups and intraperitoneal or PO administration route groups based on date of acquisition of the fully kindled state such that all groups were balanced to include both mice that achieved the early and those that achieved the late kindling 
criterion. Sham-kindled mice were randomized within cages. Mice were stimulated or sham-stimulated 24 hours prior to each MC or SAL administration day to ensure the stability of the stage 5 seizure, consistent with our drug-screening protocols in CKM (Barker-Haliski et al., 2016, 2017a; Koneval et al., 2018). The following day, mice were administered either SAL or MC by the assigned route of administration twice weekly for 6 weeks. Health assessments were performed at four time points during the study period by a veterinarian blinded to kindling status and treatment group.

At the conclusion of the 6-week MC/SAL administration period, mice were euthanized via $\mathrm{CO}_{2}$ asphyxiation using a gradual displacement method (10\%-30\% volume per minute) according to the 2013 AVMA Guidelines for the Euthanasia of Animals (https:// www.avma.org/KB/Policies/Documents/euthanasia.pdf). Blood was collected via cardiocentesis from a subset of mice immediately following euthanasia and placed directly into blood tubes containing EDTA (BD Microtainer Tubes with EDTA; BD Biosciences, San Jose, CA) and serum separator tubes (BD Microtainer Serum Separator Tubes, gold; BD Biosciences). Serum was separated by centrifugation (9000 relative centrifugal force $\times 5$ minutes) within 2 hours of collection, and serum and whole blood from a subset of animals (CKM: i.p. MC, $n=6$; i.p. SAL, $n=5$; PO MC, $n=3$; SHAM: i.p. MC, $n=5$; i.p. SAL, $n=4$; PO MC, $n=5$; PO SAL, $n=5$ ) were submitted to a veterinary diagnostic laboratory for complete blood count and clinical serum biochemistry profiling (Phoenix Central Laboratories, Mukilteo, WA). Necropsies were performed on all animals within the study. Histopathology was performed on a subset of animals from each experimental treatment group (CKM: i.p. MC, $n=7$; i.p. SAL, $n=6$; PO MC, $n=5$; PO SAL, $n=3$; SHAM: i.p. MC, $n=6$; i.p. SAL, $n=6$; PO MC, $n=5$; PO SAL, $n=5$ ).

Open Field Testing. An automated open field (OF) activity assessment was performed by an investigator blinded to treatment group at the end of the 6-week MC/SAL treatment period for all mice administered intraperitoneal MC/SAL (sham vs. CKM), as previously described (Barker-Haliski et al., 2015, 2017a; Koneval et al., 2018). In this assay, each mouse was habituated to the testing room for at least 1 hour. The rodent was then placed into the center of a Plexiglas OF chamber $[40 \times 40 \times 30 \mathrm{~cm}$ (length $\times$ width $\times$ height) $]$ equipped with infrared sensors to detect animal movement for 10 minutes. During the 10minute period, the total distance traveled (centimeters), vertical activity counts, and horizontal activity counts were measured and recorded by an automated software program (Omnitech Electronics, Columbus, OH).

Health Assessment. Mice were weighed weekly throughout the study. In addition, physical health was assessed using a visual clinical examination scoring system (Table 1) adapted from previously published visual scoring systems used to assess overall health of mice (Rex et al., 2016; Mai et al., 2018). Animals were assessed for their general appearance, behavior, body condition (Ullman-Cullere and Foltz, 1999), and overall clinical condition by a single investigator (S.M.) blinded to experimental treatments. Within each of those categories, animals were assigned a score of $0-3$ based on the presence or absence of various abnormal signs or symptoms. The scores from each category were summed to determine an overall clinical score (range of $0-11$ ). Animals were scored at four separate time points throughout the study: 1) 1 week after kindling acquisition, prior to the initial administration of MC/SAL; 2) after 1 week of MC/SAL treatment; 3) after 2.5 weeks of MC/SAL treatment; and 4) after 6 weeks of MC/SAL treatment. Care was taken to perform assessments at approximately the same time of day. Mice were assessed within their home cages by the observer inside the animal housing room shortly after each cage was opened within a laminar flow hood. Mice infected with influenza were similarly assessed on the second clinical exam, 8 days post infection.

Histology. Tissues were fixed in $10 \%$ neutral buffered formalin, embedded in paraffin, sectioned, and stained with hematoxylin and eosin. Sections of lung, thymus, heart, kidney, liver, spleen, salivary glands, pancreas, mesentery, lymph nodes, male reproductive tract, bladder, stomach, intestines, and decalcified cross sections of the cranial and caudal portions of the head were evaluated microscopically by a board-certified veterinary pathologist (P.M.T.) masked to experimental treatments. All tissues were visually scanned for the presence or absence of foam-laden macrophages [foam cells (FCs)]. A subset of tissues was selected for further semiquantification of the number and extent of FCs present, based on repeated observation of FCs in those tissues among multiple animals. Tissues included in the scoring were as follows: liver, lung, kidney, spleen, mesentery, arteries, and choroid. Each tissue was assigned an FC score to semiquantify the number of FCs present and a tissue damage score to capture the presence or absence of degeneration and/or necrosis associated with FCs (Table 2). A total disease score was determined by first multiplying the FC score by the tissue damage multiplier for each tissue and then summing the number of affected tissues plus the individual tissue scores within a mouse. To further characterize the material contained within the FCs, and secondary tissue damage (fibrosis), a subset of tissues was selected and stained with periodic acid-Schiff (PAS) and Masson's trichrome stain.

Statistics. Group sizes were based on our well established kindling acquisition rates and powered for histopathological analysis. Histopathology with a minimum group size of $n=3$ gives $80 \%$ power at $95 \%$ significance to detect a $1.5-$ S.D. difference in disease score between treatment groups. Our historical experience with corneal kindling indicates that $>60 \%$ of $\mathrm{CF}-1$ mice achieve the fully kindled state after 3 weeks of corneal stimulation (BarkerHaliski et al., 2017a; Koneval et al., 2018). Rate of corneal kindling acquisition was analyzed by repeat-measures ANOVA (kindling group $\times$ time), with a post hoc Bonferroni test. Change in body weight during the MC/SAL treatment period was analyzed by repeat-measures ANOVA (treatment condition $\times$ time), with a post hoc Bonferroni test. Clinical examination was analyzed by

TABLE 1

Clinical assessment parameters and scoring

\begin{tabular}{|c|c|c|c|c|}
\hline & \multicolumn{4}{|c|}{ Score } \\
\hline & 0 & 1 & 2 & 3 \\
\hline Appearance & Normal & $\begin{array}{l}\text { Lack of grooming, sunken eyes, mild } \\
\text { blepharitis/blepharospasm, mild } \\
\text { hunched posture }\end{array}$ & $\begin{array}{l}\text { Ocular discharge, corneal ulceration, marked } \\
\text { blepharitis/blepharospasm, prolonged hunched } \\
\text { posture, abdominal distention, head tilt }\end{array}$ & $\begin{array}{l}\text { Hunched unmoving } \\
\text { posture, labored } \\
\text { breathing }\end{array}$ \\
\hline $\begin{array}{c}\text { Clinical } \\
\text { signs }\end{array}$ & None & $\begin{array}{l}\text { Elevated or decreased respiratory and/or } \\
\text { effort }\end{array}$ & Clinical dehydration, marked pallor & \\
\hline Behavior & Normal & $\begin{array}{l}\text { Decreased interaction with cagemates, } \\
\text { slow to move about cage, decreased } \\
\text { interest in environment }\end{array}$ & $\begin{array}{l}\text { Isolated from cagemates, slow to move when } \\
\text { stimulated, impaired mobility, ataxia, hypo- or } \\
\text { hyperesthetic when handled }\end{array}$ & $\begin{array}{l}\text { Immobile, weakly or not } \\
\text { responsive to handling, } \\
\text { convulsing }\end{array}$ \\
\hline $\begin{array}{l}\text { Body } \\
\text { condition }\end{array}$ & $\begin{array}{l}\text { BCS } \\
\quad \geq 3\end{array}$ & BCS 2 to 3 & BCS 1 to 2 & $\mathrm{BCS} \leq 1$ \\
\hline
\end{tabular}

BCS, Body Condition Score. 
TABLE 2

FC scoring system

\begin{tabular}{ll}
\hline FC Score & \\
\hline 0 & No FCs present \\
1 & Scattered individual FCs present within the tissue (1-5 cells) \\
2 & Clusters of FCs present, no inflammation \\
3 & Clusters of FCs present with inflammation, or coalescing clusters of FCs without inflammation \\
4 & Coalescing clusters of FCs with inflammation \\
Tissue damage multiplier & \\
1 & No tissue damage present \\
2 & Presence of degeneration or necrosis \\
\hline
\end{tabular}

repeat-measures ANOVA (treatment condition $\times$ time). OF data were analyzed by a two-factor ANOVA (kindling $\times$ treatment). Histopathologic disease scores, hematology results, and serum biochemistry analytes were analyzed by one-way ANOVA with a post hoc Tukey multiple comparison test. For all tests, $P<0.05$ was considered statistically significant. All statistical analyses were performed in GraphPad versions 5.0 or later (GraphPad Software, La Jolla, CA).

\section{Results}

Repeated Administration of Low-Concentration MC or SAL Does Not Affect Body Weight Gain or
Long-Term Kindled Seizure Stability after Corneal Kindling. Corneal kindling of male CF-1 mice typically results in $60 \%-80 \%$ of animals achieving the fully kindled state (Koneval et al., 2018). In this study, 72\% (34/47) of mice achieved the criterion (Fig. 1A). There was no effect of repeated administration of MC or SAL on the stability of the corneal-kindled seizure during the 6-week study period $\left(\mathrm{F}_{(10,176)}=0.2788, P>0.9\right.$; Fig. $\left.1 \mathrm{~B}\right)$; all mice consistently demonstrated secondarily generalized Racine stage 4 or 5 seizures throughout the testing period.

Animals were randomized to treatment after acquisition of the kindled state to evenly distribute kindled states across

B Kindled Seizure Stability

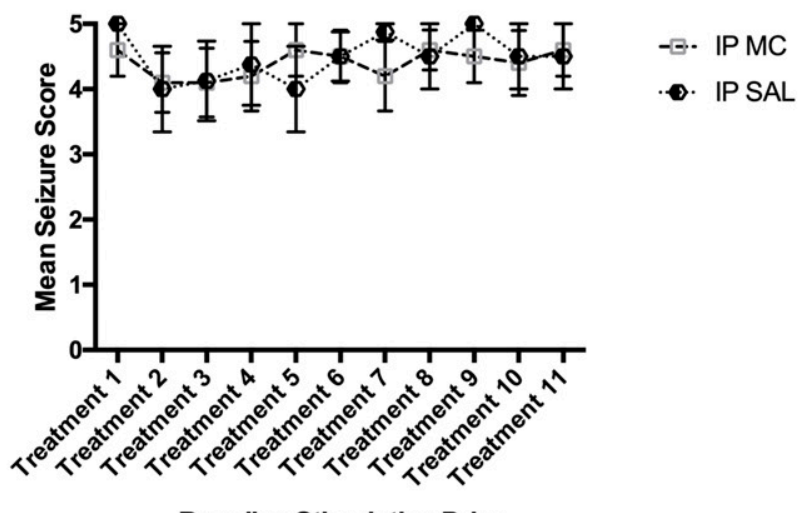

Baseline Stimulation Prior

D

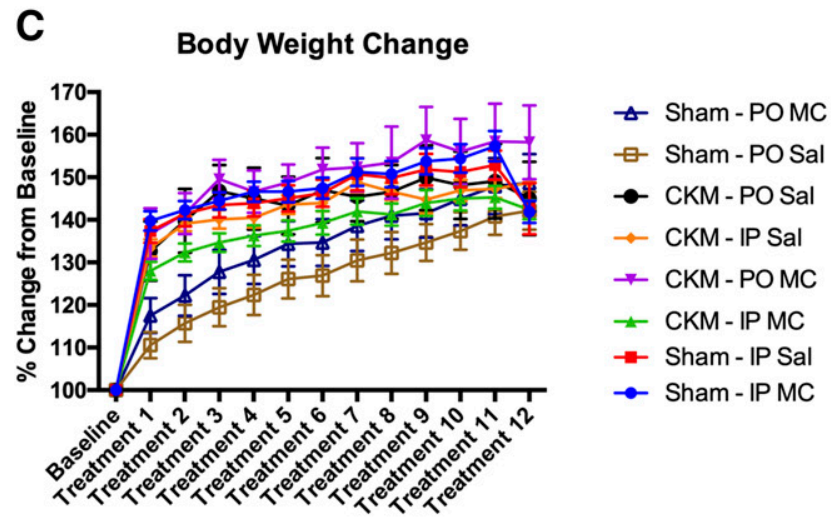

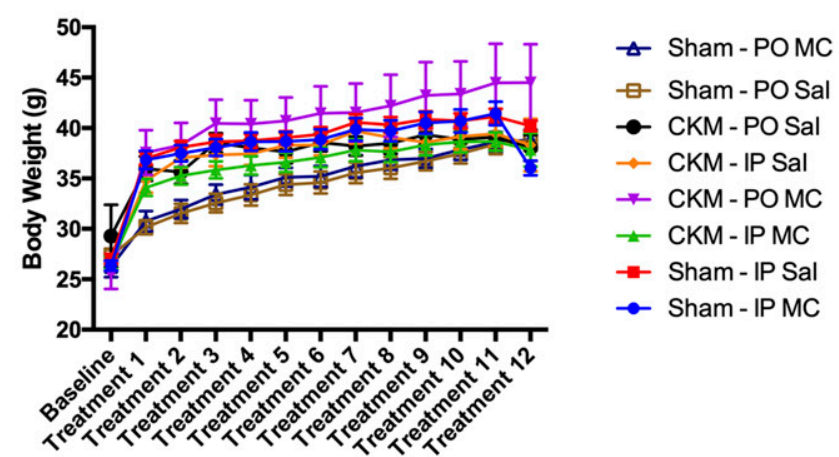

Fig. 1. Repeated administration of MC by the PO and intraperitoneal routes does not overtly impact body weight gain or long-term stability of the fully kindled seizure after acquisition of the fully kindled state. (A) Over $72 \%$ of mice that enrolled in the corneal-kindling protocol achieved the fully kindled state within 3 to 4 weeks. Sham-kindled mice did not present with a behavioral seizure during any of the stimulation sessions. $N=47 \mathrm{CKM}$ and $N=35$ sham. (B) The long-term stability of the fully kindled seizure was not adversely impacted by repeated intraperitoneal MC or SAL administration during the 6 -week testing period. (C) Animals were randomized to treatment group after acquisition of the fully kindled state, as defined by five consecutive Racine stage 5 seizures. Repeated administration of MC or SAL by the intraperitoneal or PO route to sham- or corneal-kindled mice was not associated with any overt impacts on percentage change $(C)$ or raw change $(D)$ in body weight gain during the 6 -week treatment period. CKM: i.p. MC, $n=14$; i.p. SAL, $n=12$; PO MC, $n=5$; PO SAL, $n=3$; sham-kindled mice: i.p. MC, $n=13$; i.p. SAL, $n=12$; PO MC, $n=5$; PO SAL, $n=5$. 
treatment groups. There was no time $\times$ treatment effect on the percentage change in body weight gain during the 6 -week MC/ SAL treatment period $\left(\mathrm{F}_{(5,11)}=0.7145, P>0.6\right.$; Fig. $\left.1 \mathrm{C}\right)$. There was also no overt effect of any treatment on raw body weight gain during the treatment period (Fig. 1D).

Clinical Examination during the Treatment Period Reveals No Overt Effects of Repeated Low-Concentration Intraperitoneal MC Administration in CKM or Sham-Kindled Mice. A veterinarian blinded to treatment and kindling status assessed general appearance, behavior, and activity of each animal at four separate time points during the 6 -week treatment period to determine if there was any impact of treatment on general health of the animals. All mice appeared clinically healthy, active, and in good body condition throughout the study period. There were no treatment $\times$ kindling group effects at any point during the monitoring period $\left(\mathrm{F}_{(15,39)}=0.3955, P>0.9\right.$; Fig. 2A). For comparison, mice infected with influenza A virus and similarly scored with this clinical examination criteria 8 days post infection demonstrated an average clinical disease score of $4.8 \pm 0.13$ (Fig. 2B).

Open Field Assessment Reveals No Effect of Repeated Intraperitoneal MC Administration on Behavioral Comorbidities of Epilepsy. OF activity is a commonly used moderate-throughput means to assess behavioral deficits in rodents. We and others have demonstrated that CKMs demonstrate increased exploratory activity (indicative of spatial memory deficit) and/or increased perimeter-seeking behavior (thigmotaxis; indicative of anxiety-like behavior) in this task (Albertini et al., 2018; Koneval et al., 2018), consistent with clinical reports of these behavioral comorbidities in human patients with epilepsy (Brooks-Kayal et al., 2013). Thus, to define whether repeated intraperitoneal MC or SAL impacted any behavioral aspects of the CKM model, which could impact the overall phenotype of this preclinical model, we assessed OF exploration and thigmotaxis of mice after the final MC/SAL treatment. Because pilot studies of $\mathrm{PO}$ administration of MC did not reveal any histopathological lesions or OF deficits in any of the mice treated by this route, our group size was powered for histology instead of behavior for the PO
MC/SAL sham and CKM treatment groups, and thus, these groups were not evaluated for exploratory behavior in the OF. There was a main effect of kindling $\left(\mathrm{F}_{(1,41)}=11.04\right.$, $P<0.0019$ ) on total distance traveled within the $\mathrm{OF}$, but no significant effect of intraperitoneal MC treatment $\left(\mathrm{F}_{(1,41)}=0.0797, P>0.7\right.$; Fig. 3A). There was no effect of treatment or kindling on distance traveled within the center of the $\mathrm{OF}$ (kindling: $\mathrm{F}_{(1,42)}=0.004681, P>0.9$; treatment: $\mathrm{F}_{(1,42)}=0.7577, P>0.3$; Fig. $\left.3 \mathrm{~B}\right)$. There was also no effect of treatment on vertical rearing activity in the center of the $\mathrm{OF}$ (kindling: $\mathrm{F}_{(1,43)}=0.3245, P>0.5$; treatment: $F_{(1,43)}=0.2987$; Fig. 3C) or percentage of total time at rest in the $\mathrm{OF}$ center (kindling: $\mathrm{F}_{(1,42)}=1.179$, $P>0.2$; treatment: $\mathrm{F}_{(1,42)}=0.0016, P>0.9$; Fig. 3D). Thus, 6 weeks of repeated administration of MC by the intraperitoneal route was not associated with marked alterations in behavioral comorbidities of chronic seizures in CKM, which could have been otherwise useful to cue an investigator to the effect of the vehicle versus investigational drug in this model.

Repeated Intraperitoneal Administration of MC Does Not Affect Routine Hematology or Serum Chemistry Parameters. Previous reports suggest that repeated, high-concentration, long-duration intraperitoneal MC administration can lead to erythrophagocytosis and anemia in mice, rats, and dogs (Teoh, 1961; Weissman et al., 1961; Fitch et al., 1962; Rowley et al., 1962; Salman et al., 2006). In addition, chronic administration of high-concentration, longduration intraperitoneal MC in mice resulted in changes in circulating white blood cell profiles, with significant decreases in circulating lymphocytes and increases in circulating monocytes and polymorphonuclear cells (Salman et al., 2006). To determine if repeated, low-concentration intraperitoneal MC administration could induce changes in circulating red or white blood cells in CKM or sham-kindled mice, we collected blood from intraperitoneal and PO MCand SAL-treated mice at the time of euthanasia $(n=4-6$ mice/group). There was no evidence of anemia associated with low-concentration intraperitoneal MC administration in our study, demonstrated by similar values in red blood cell number, hematocrit, or hemoglobin concentration
A

Clinical Exams

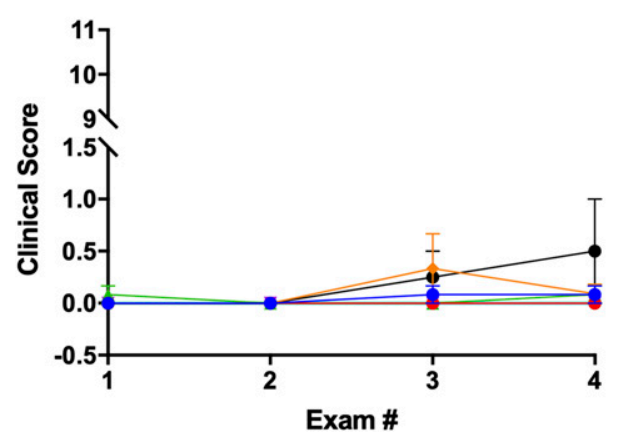

B

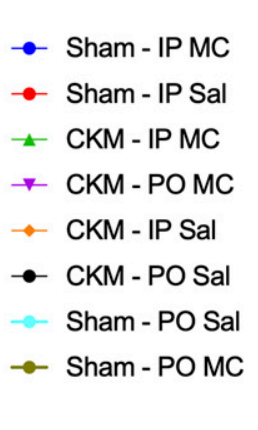

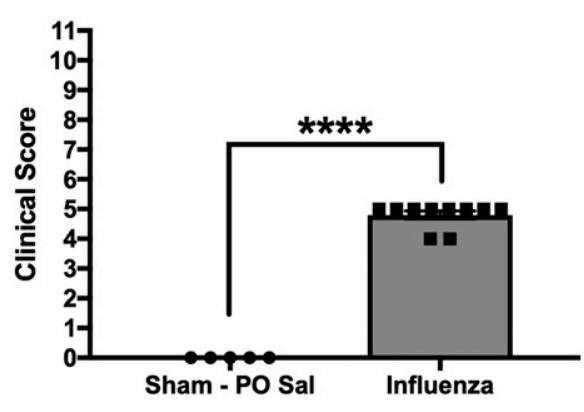

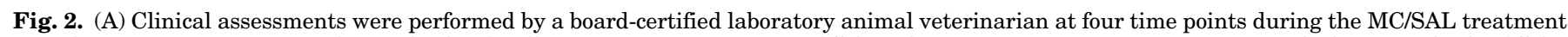

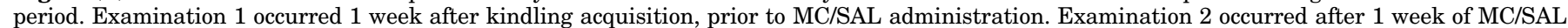

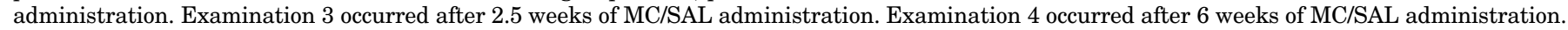

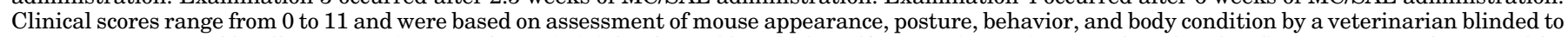

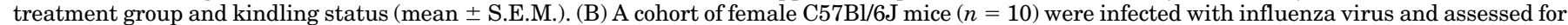

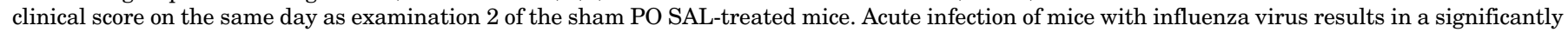

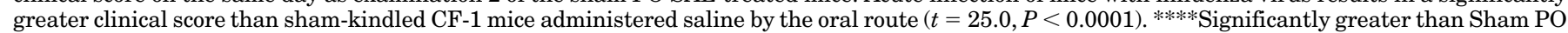
SAL $(P<0.0001)$. 
A

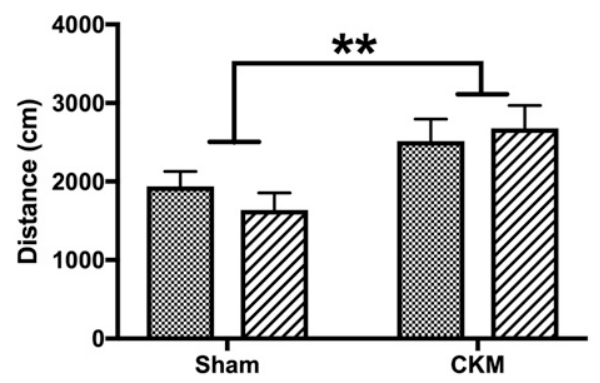

C

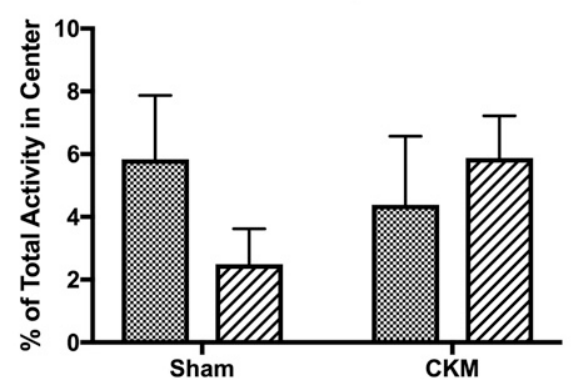

B
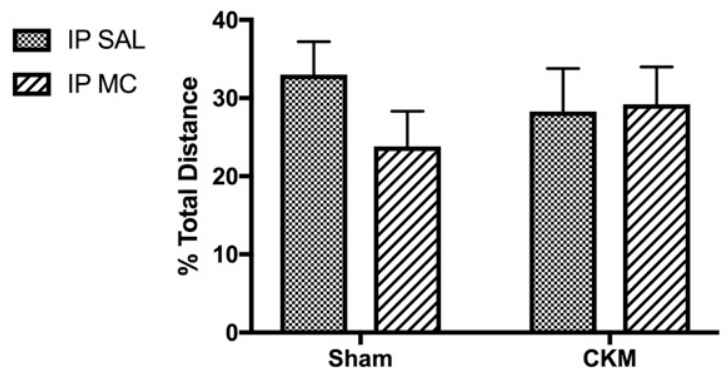

D Rest Time in Center

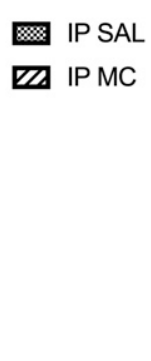

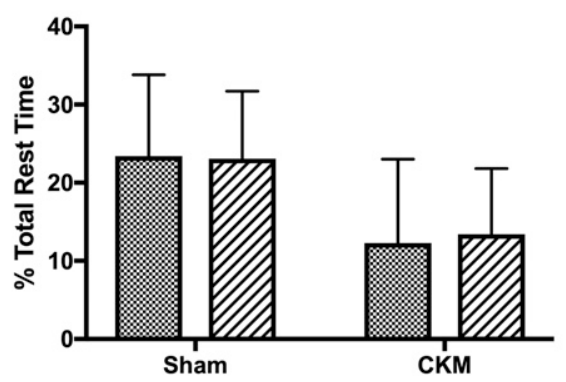

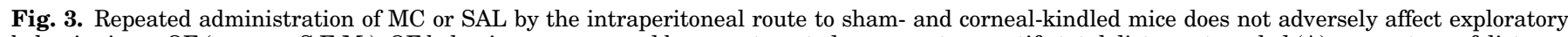

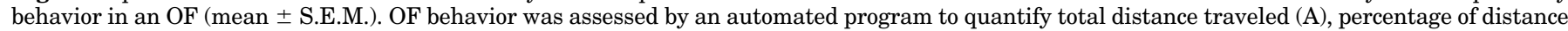

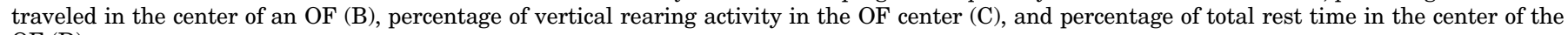
OF (D).

between intraperitoneal and PO MC- and SAL-treated mice (Table 3). Similarly, there were no differences observed in circulating white blood cell numbers between mice that received intraperitoneal MC versus SAL (Table 3). Interestingly, whereas all parameters were within a range considered biologically normal, neutrophil and monocyte counts were higher in animals that received repeated intraperitoneal injections (SAL or MC). In addition to anemia, repeated high-concentration intraperitoneal MC administration has been associated with alterations in clinical chemistry parameters, such as blood urea nitrogen concentrations (Weissman et al., 1961). We therefore sought to evaluate if low-concentration intraperitoneal MC influenced standard serum biochemistry profiles in our model. We analyzed serum collected at the time of euthanasia from PO or intraperitoneal MC- and SAL-treated animals for 12 different serum analytes, including blood urea nitrogen, calcium, phosphorus, and liver enzymes. Again, all parameters were within a biologically normal range, and no significant differences were observed between animals that received intraperitoneal MC versus SAL (Table 4).

Histopathological Assessment after 6 Weeks of Repeated Low-Concentration Intraperitoneal MC Administration Reveals Widespread Accumulation of MC-Laden Foam Cells. Necropsy at the completion of inlife testing revealed no significant gross lesions in any animal, regardless of treatment group. Histopathological assessment, however, revealed widespread accumulations of large FCs (interpreted as macrophages containing MC) in multiple tissues in all of the intraperitoneal MC-treated mice, regardless of kindling status (Figs. 4-6). To further characterize the vacuolated material within the FCs, we performed PAS staining on selected tissues. Consistent with previous findings (Roth and Krinke, 1994), PAS staining of the FCs was primarily negative (Fig. $5 \mathrm{~F}$, inset), with rare cells having light-pink punctate cytoplasmic uptake, suggesting that the large vacuoles within FCs contained MC rather than glycogen or other polysaccharide accumulations. Tissues from SAL-treated mice, as well as animals receiving $\mathrm{MC}$ via the $\mathrm{PO}$ route, were normal (Fig. 4, A, C, and $\mathrm{E}$ ). Organs affected in the intraperitoneal MC-treated group included the liver, lung, kidney, spleen, mesentery, large arteries, and choroid plexus. The FC aggregates ranged in size and severity from single FCs within an affected tissue to coalescing clusters of FCs (Figs. 4, B, D, and F, and 5). In some cases, the FCs were attended by inflammatory cells (most often lymphocytes and histiocytes with occasional neutrophils; Figs. 4D and 5, C and E). In some of the larger foci, there was secondary tissue damage, such as glomerulonephritis (Fig. 5F), minimally increased hepatic fibrosis (Fig. 5D), or mesenteric necrosis (data not shown). FCs were noted in one animal in the lumen of the carotid artery (Fig. 5A) associated with large accumulations of FCs in the intimal and subintimal regions (Figs. $4 \mathrm{~F}$ and $5 \mathrm{~A}$ ). Similar intimal and subintimal accumulations were present in the aortas of two animals (data not shown). Within the central nervous system (CNS), FC accumulations were noted in the choroid (Fig. 5B) with no attending inflammation. A total disease score was developed as outlined in Table 2 to better quantify the presence and extent of FCs and tissue damage associated with each treatment group. Only animals receiving intraperitoneal MC demonstrated a quantifiable disease score (Fig. 6); however, there was no significant difference between the lesions observed in CKM versus sham-kindled mice. With the exception of a few scattered FCs within the spleens of MC-treated mice, there were no 


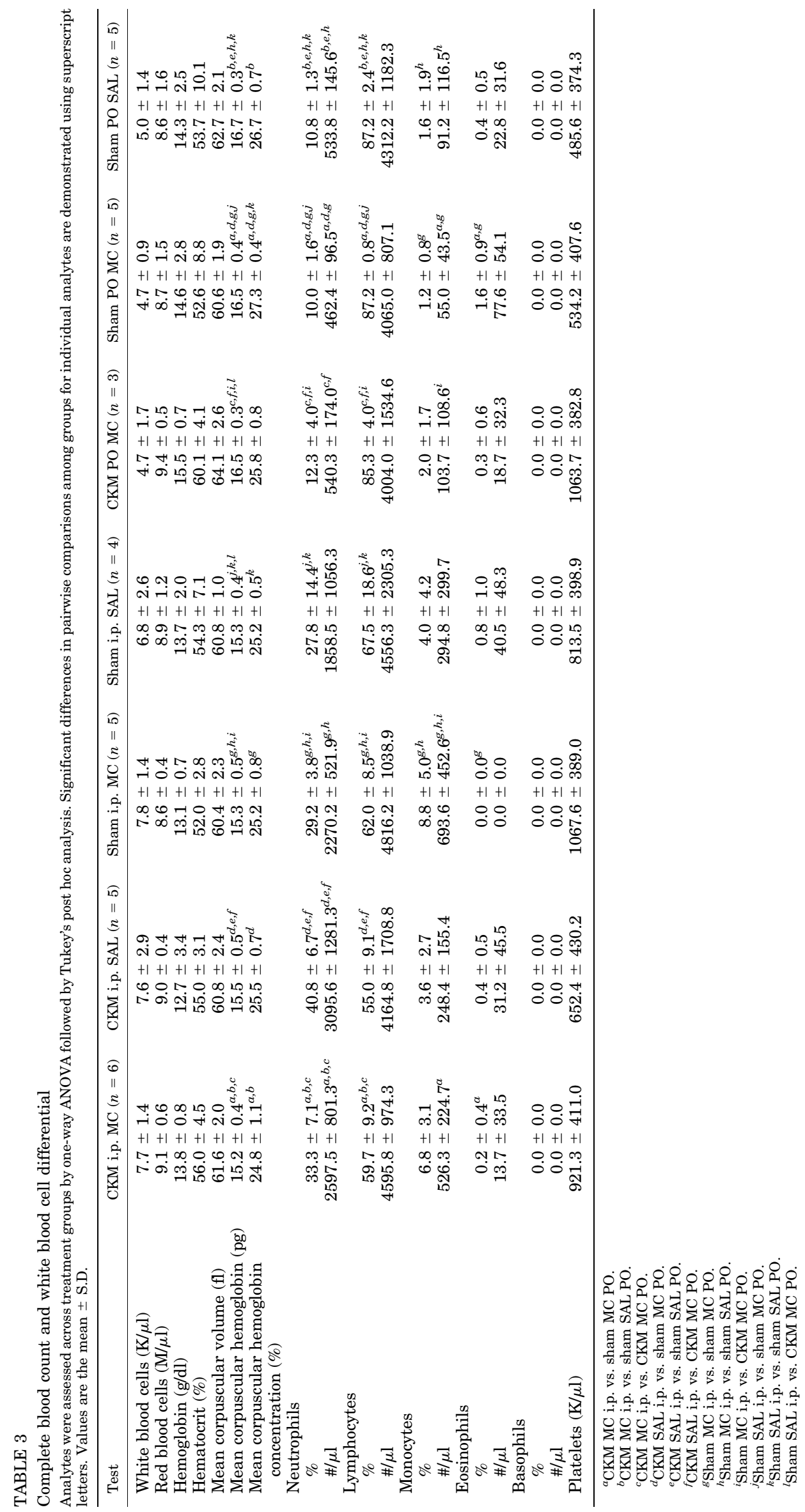


TABLE 4

Serum biochemistry analytes

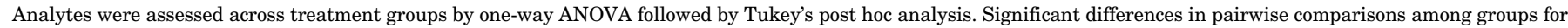
individual analytes are demonstrated using superscript letters. Values are the mean \pm S.D.

\begin{tabular}{|c|c|c|c|c|c|c|c|}
\hline Test & $\begin{array}{l}\text { CKM i.p. MC } \\
\quad(n=6)\end{array}$ & $\begin{array}{l}\text { CKM i.p. SAL }(n= \\
5)\end{array}$ & $\begin{array}{l}\text { Sham i.p. MC } \\
(n=5)\end{array}$ & $\begin{array}{l}\text { Sham i.p. SAL } \\
\qquad(n=4)\end{array}$ & 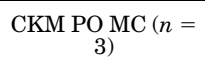 & $\begin{array}{c}\text { Sham PO MC }(n= \\
5)\end{array}$ & $\begin{array}{l}\text { Sham PO SAL } \\
\quad(n=5)\end{array}$ \\
\hline Glucose (mg/dl) & $274.5 \pm 44.5$ & $282.0 \pm 49.6$ & $319.2 \pm 108.2$ & $268.0 \pm 53.5$ & $281.0 \pm 48.7$ & $357.0 \pm 77.7$ & $269.6 \pm 55.5$ \\
\hline $\begin{array}{l}\text { Blood urea nitrogen } \\
(\mathrm{mg} / \mathrm{dl})\end{array}$ & $25.2 \pm 1.8^{a}$ & $21.6 \pm 3.3$ & $26.0 \pm 3.5^{b}$ & $22.5 \pm 3.3$ & $22.7 \pm 3.8$ & $19.4 \pm 2.1^{a, b}$ & $22.2 \pm 2.6$ \\
\hline Calcium (mg/dl) & $10.8 \pm 0.9$ & $10.9 \pm 0.6$ & $11.4 \pm 0.5$ & $10.7 \pm 0.3$ & $10.3 \pm 0.4$ & $11.3 \pm 0.7$ & $10.4 \pm 0.4$ \\
\hline Phosphate (mg/dl) & $14.7 \pm 1.9$ & $14.3 \pm 1.4$ & $13.9 \pm 1.1$ & $14.2 \pm 0.3$ & $12.8 \pm 2.2$ & $14.6 \pm 1.8$ & $13.3 \pm 0.7$ \\
\hline Total protein (g/dl) & $6.1 \pm 0.5$ & $6.1 \pm 0.5$ & $5.8 \pm 0.4$ & $5.9 \pm 0.3$ & $5.7 \pm 0.2$ & $5.8 \pm 0.2$ & $5.5 \pm 0.3$ \\
\hline Albumin (g/dl) & $3.5 \pm 0.2$ & $3.5 \pm 0.2$ & $3.2 \pm 0.2$ & $3.3 \pm 0.1$ & $3.5 \pm 0.3$ & $3.5 \pm 0.2$ & $3.5 \pm 0.2$ \\
\hline Globulin (g/dl) & $2.6 \pm 0.3^{c}$ & $2.6 \pm 0.3$ & $2.6 \pm 0.2^{d}$ & $2.6 \pm 0.3^{e}$ & $2.2 \pm 0.1$ & $2.3 \pm 0.1$ & $2.0 \pm 0.2^{c, d, e}$ \\
\hline Total bilirubin (mg/dl) & $0.2 \pm 0.1$ & $0.2 \pm 0.1$ & $0.1 \pm 0.0$ & $0.2 \pm 0.1$ & $0.2 \pm 0.1$ & $0.2 \pm 0.1$ & $0.1 \pm 0.1$ \\
\hline $\begin{array}{l}\text { Alkaline phosphatase } \\
(\mathrm{U} / \mathrm{l})\end{array}$ & $125.5 \pm 43.3$ & $178.4 \pm 57.9^{f}$ & $83.6 \pm 26.4^{f, b}$ & $157.0 \pm 41.0$ & $132.0 \pm 25.2$ & $189.8 \pm 65.4^{b}$ & $152.6 \pm 24.5$ \\
\hline $\begin{array}{l}\text { Alanine } \\
\quad \text { aminotransferase (U/1) }\end{array}$ & $54.7 \pm 25.8$ & $55.6 \pm 24.4$ & $43.8 \pm 10.1$ & $40.8 \pm 11.8$ & $46.0 \pm 12.8$ & $37.6 \pm 13.1$ & $37.0 \pm 7.3$ \\
\hline $\begin{array}{l}\text { Aspartate } \\
\quad \text { aminotransferase (U/l) }\end{array}$ & $251.2 \pm 335.9$ & $100.4 \pm 36.7$ & $62.6 \pm 19.8$ & $85.0 \pm 31.8$ & $70.0 \pm 14.0$ & $70.2 \pm 40.4$ & $89.4 \pm 66.2$ \\
\hline Cholesterol (mg/dl) & $142.2 \pm 40.8$ & $148.0 \pm 26.1$ & $142.0 \pm 18.5$ & $149.0 \pm 17.4$ & $133.3 \pm 16.0$ & $165.8 \pm 18.5$ & $138.2 \pm 27.3$ \\
\hline
\end{tabular}

${ }^{a}$ CKM MC i.p. vs. sham MC PO

${ }^{b}$ Sham MC i.p. vs. sham MC PO.

${ }^{c}$ CKM MC i.p. vs. sham SAL PO.

${ }^{d}$ Sham MC i.p. vs. sham SAL PO.

${ }^{e}$ CKM MC PO vs. sham SAL PO.

${ }^{f}$ CKM SAL i.p. vs. sham MC i.p.

morphologic differences between the groups observed grossly or histologically (data not shown). Similarly, the bone marrow was not different histologically (data not shown). In both intraperitoneal SAL- and intraperitoneal MC-treated animals, there was mild to moderate mesenteric inflammation consistent with repeated intraperitoneal injections. In the intraperitoneal MC-treated mice, occasional mesenteric inflammatory foci contained clusters of FCs (Fig. 5E).

\section{Discussion}

MC is a commonly used formulation vehicle for preclinical studies because it is considered benign and well tolerated in laboratory animals (Gad et al., 2006). Despite frequent use,
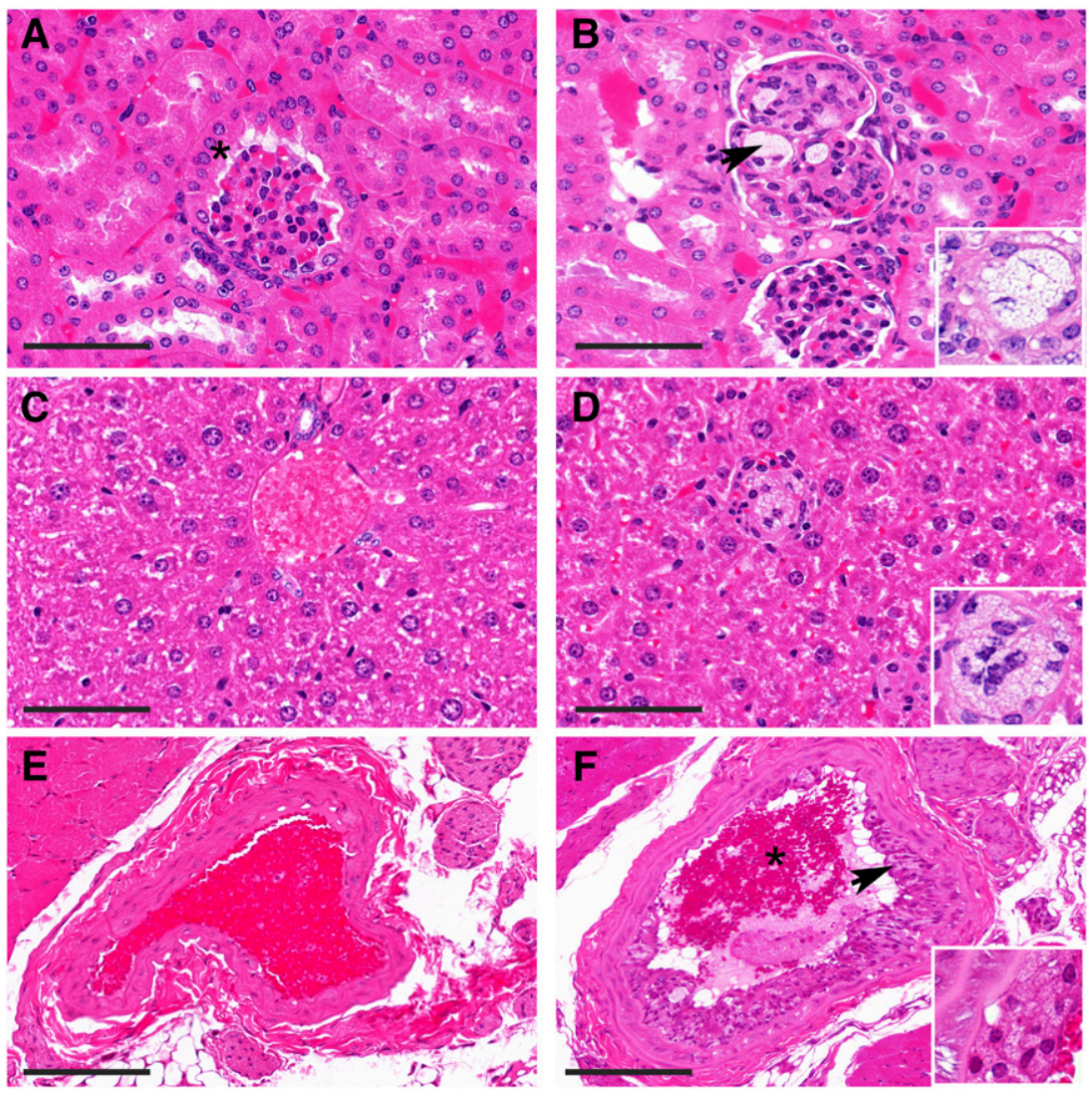

Fig. 4. Representative sections from kidney (A and B), liver $(\mathrm{C}$ and $\mathrm{D})$, and carotid artery (E and F). (A, C, and E) Normal tissues from an intraperitoneal SAL-treated mouse. (A) Note that male mice have cuboidal parietal epithelium lining the glomerular capsule (asterisk). (B, D, and F) Tissues from an intraperitoneal MC-treated mouse; insets show high-magnification examples of FCs. (B) Glomerulus containing large foamy cells (arrow), enlarged with proliferative glomerulonephropathy. (D) Liver foci of FCs with surrounding mononuclear inflammatory cells. (Inset) High magnification of FCs without attending inflammation. (F) Carotid artery with abundant subintimal accumulations of FCs (arrow); lumen indicated (asterisk). (A-D) Original magnification, $200 \times$. (E and F) Original magnification, 100 $\times$. (Insets) Original magnification, $400 \times$. 

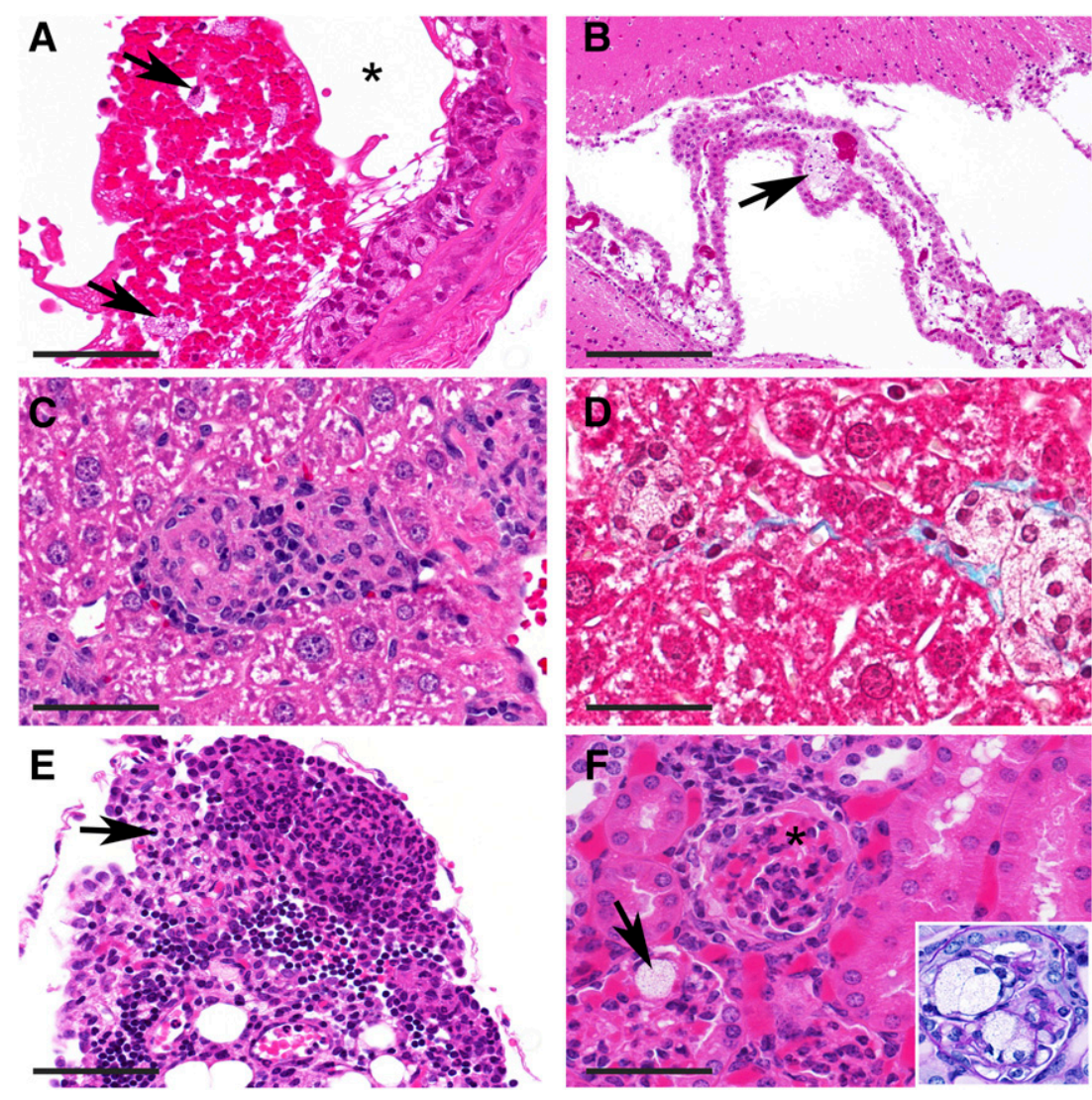
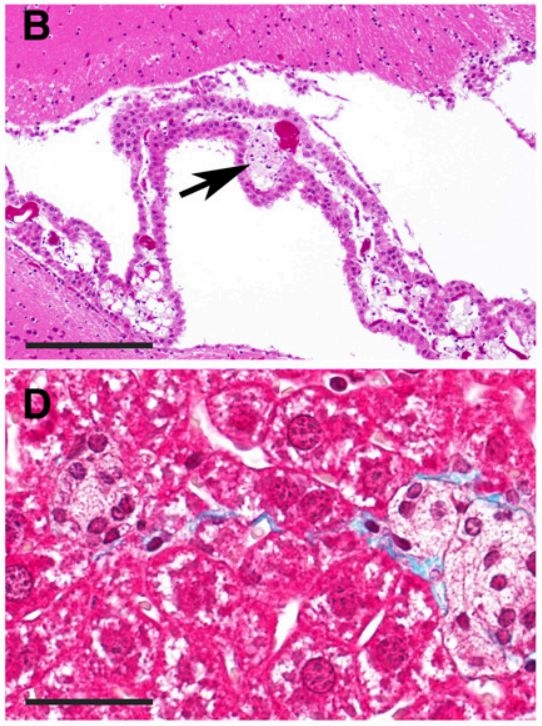

Fig. 5. FCs are present in multiple organs and may be associated with inflammation and tissue damage. (A) Carotid artery. Note abundant intimal and subintimal accumulation of FCs, with FCs present within the lumen (asterisk). Original magnification, $400 \times$. (B) Choroid plexus contains moderate perivascular accumulations of FCs (arrow). Original magnification, $100 \times$. (C) Liver with coalescing microgranulomas. Original magnification, $200 \times$. (D) Liver Mason's trichrome stain for fibrosis (blue stain); there is a small amount of increased connective tissue (blue) adjacent to foci of FCs. Original magnification, $400 \times$. (E) Mesentery. Mixed inflammatory foci adjacent to accumulations of FCs (arrow). Original magnification, $400 \times$. (F) Glomerulonephritis (asterisk) and FCs within affected glomeruli (arrow). Original magnification, $400 \times$. (Inset) PAS-stained glomerulus with intracapillary FCs . The cells are PAS negative. Original magnification, $400 \times$. we herein demonstrate that repeated administration (twice weekly) of low-concentration MC (0.5\%) via the intraperitoneal, but not $\mathrm{PO}$, route to both sham and CKM is associated with widespread systemic accumulation of MCladen macrophages. This present MC administration protocol was not associated with overt evidence of behavioral deficits that could otherwise indicate a general impact on the preclinical model phenotype; mice demonstrated no differences in body weight gain, stability of kindled seizures, clinical disease score, or behavioral deficits after 6 weeks of twice-weekly intraperitoneal MC administration. Furthermore, there were no significant changes in clinical hematology or serum biochemistry profiles associated with the repeated intraperitoneal MC regimen. Thus, despite the histopathology in multiple organ systems, intraperitoneal MC-treated mice in our present study were visibly and behaviorally comparable to intraperitoneal SAL- and PO MC-treated counterparts, regardless of kindling status. Repeated administration of MC via the intraperitoneal route at the concentration delivered $(0.5 \%)$ was not found to be overtly detrimental to the overall wellbeing of the mice in this study. We thus demonstrate that the only appreciable impact of repeated intraperitoneal administration of low-concentration MC on the CKM model of epilepsy is systemic histopathological lesions in multiple organs. These findings indicate that lowconcentration intraperitoneal MC could lead to organ damage that would not manifest on effects on the model phenotype but would potentially be inappropriately attributed to an investigational agent in the absence of vehicle-controlled histopathology.
Chronic administration of high-concentration intraperitoneal MC has been historically used to induce hypersplenism and anemia in dogs, mice, and rats (Palmer et al., 1953; Weissman et al., 1961; Fitch et al., 1962; Rowley et al., 1962; Salman et al., 2006). Following a $2 \times$ /week intraperitoneal MC administration for 12-15 weeks, Palmer et al. (1953) and later Weissman et al. (1961) induced splenomegaly. Further, those

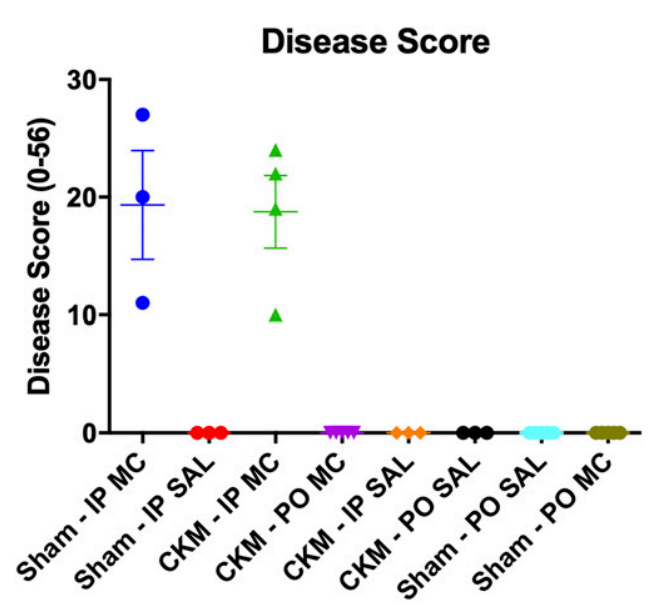

Fig. 6. Administration of $\mathrm{MC}$ results in $\mathrm{FC}$ accumulation when administered by the intraperitoneal route, but not the PO route, regardless of kindling status. Liver, lung, kidney, spleen, mesentery, arteries, and choroid were assessed histologically by a veterinary pathologist masked to experimental treatment. A total disease score, ranging from 0 to 56 , was developed to capture the presence and extent of FCs in the tissues as well as the presence or absence of degeneration and/or necrosis associated with the FC aggregates (mean \pm S.E.M.). 
animals demonstrated accumulation of opaque, straw-colored ascetic fluid in the abdomen and whitish-gray areas on spleens themselves (Palmer et al., 1953). Of note, our study used significantly fewer intraperitoneal MC administration days (12) and a lower MC concentration (0.5\%) than these prior studies. Necropsy of all animals in the study demonstrated no signs of overt hypersplenism; spleens were grossly normal in all groups. We did not detect any ascetic fluid, and histologically there were low numbers of FCs present within the splenic parenchyma and no evidence of pathologic erythrophagocytosis. Nonetheless, few reports exist in the extant literature to point to any potential adverse histologic effects of repeated intraperitoneal administration of low-concentration MC in laboratory rodents. In this regard, the present study indicates that while repeated low-concentration MC administered intraperitoneally may be associated with systemic histopathology, this does not manifest in loss of behavioral fidelity of the preclinical model. The repeated intraperitoneal administration of any substance can cause some degree of mesenteric inflammation (Hubbard et al., 2017). With the exception of occasional clusters of FCs within some mesenteric inflammatory foci in MC-treated mice, the mesenteric inflammation was not morphologically different between groups, nor did this lesion manifest in any loss of condition or behavioral fidelity among any group.

Our histology confirms previous reports, which noted FCs in multiple tissues of MC-treated rodents. Previous publications investigating hypersplenism induced by highconcentration MC delivered by the intraperitoneal route report FCs in spleen, liver, kidney, adrenal, mesentery, lung, aorta, lymph nodes, bone marrow, and choroid (Teoh, 1961). Secondary changes to affected tissues, such as glomerulonephritis, tubulointerstitial nephritis, and massive splenomegaly with hemosiderosis and changes in clinical hematology and biochemistry profiles, were reported in studies using much greater concentrations of MC for longer periods than used in our present study (Palmer et al., 1953; Teoh, 1961; Weissman et al., 1961; Salman et al., 2006). More recently, accumulations of presumed macrophages laden with MCs in the choroid of rats injected daily and intraperitoneally with $5 \mathrm{ml} / \mathrm{kg} \mathrm{MC}(0.5 \%)$ in water have been reported (Roth and Krinke, 1994). As in our present study, they noted no behavioral or neurologic signs that could have been otherwise useful to cue an investigator to potential pathologic differences due to the formulation vehicle itself.

Intraperitoneal administration of substances is often chosen for small laboratory animals, such as rodents, where vascular access is technically challenging (Turner et al., 2011). Depending on the injectate, absorption occurs primarily via mesenteric vessels to the portal vein and thoracic lymphatics via diaphragmatic lacunae (Lukas et al., 1971; Abu-Hijleh et al., 1995). Presumably, MC and MC-laden cells access the systemic circulation and lodge most often and in greatest amounts within tissues that are well vascularized, have smallcaliber vascular channels such as glomerular and pulmonary capillaries, and have a filtration function (for example, the liver, spleen, and choroid). Direct exposure to circulating FCs or $\mathrm{MC}$ results in intimal and subintimal accumulation of FCs in large arteries, as in the carotid that we presently report. Whether other routes of administration of investigational substances, such as subcutaneous or intravenous, would be similarly associated with the presence of MC-laden cells in well vascularized tissues remains to be defined. Nonetheless, the present study demonstrates the clear need to comprehensively define whether an injectate, whether commonly used or not, is associated with any potential for adverse behavioral, hematologic, or histologic adverse effects in advance of chronic administration studies. Herein, we find that only histologic lesions were detectable to indicate adverse effects of low-concentration intraperitoneally administered MC on the physiology of both sham-kindled mice and CKM.

The CKM is a well established animal model of temporal lobe epilepsy frequently used for ASD discovery (BarkerHaliski et al., 2017a; Kehne et al., 2017). Further, this model demonstrates a pharmacological profile that is consistent with the clinically validated amygdala-kindled rat model that identified levetiracetam (Matagne and Klitgaard, 1998; Barker-Haliski, 2019). CNS inflammation is also observed in CKM (Loewen et al., 2016). It could be thus hypothesized that systemic inflammation associated with FC accumulation could be sufficient to modify the seizure phenotype of this model. Inflammation may contribute to seizure induction and maintenance (Vezzani et al., 2013); thus, one important finding of this study is that the behavioral and seizure phenotypes of animals in this study were not significantly affected by the repeated low-concentration intraperitoneal MC administration protocol when administered after acquisition of the fully kindled state, despite the presence of inflammatory cells within the periphery (i.e., outside the CNS). This intraperitoneal MC-induced systemic inflammation was not associated with any differences in the behavioral manifestation of the CKM model of epilepsy. First, the body weight gain of CKM was not impacted by repeated intraperitoneal versus PO MC or intraperitoneal/PO SAL administration. Second, the behavioral comorbidity of epilepsy (spatial memory deficits in an OF) was not affected by this repeated intraperitoneal MC administration. Finally, the stability of the kindled seizure was not impacted; all kindled mice maintained a generalized seizure throughout 6 weeks of $2 \times /$ week treatment. Thus, while it was concerning to find such widespread pathology in all intraperitoneal, but not PO, MC-treated mice, the present study highlights that histologic lesions and attending inflammation in non-CNS tissues induced by repeated, low-concentration MC do not impact the ability of CKM to reproduce behavioral facets consistent with clinical epilepsy. Systemic administration of the proinflammatory agent, lipopolysaccharide, can accelerate kindling acquisition in juvenile rats (Auvin et al., 2010a,b). Systemic accumulation of FCs and attending inflammation could have thus exacerbated the kindled seizure phenotype long term. Therefore, one important finding of our present study is that induction of peripheral histologic inflammatory lesions after the acquisition of the fully kindled state, e.g., development of epilepsy, does not exacerbate kindled seizures or modify the model phenotype in any notable regard. The present study thus further supports this hypothesis that enhanced central, but not peripheral, inflammation during, but not after, the epileptogenesis process may likely contribute more meaningfully to epileptogenesis.

Herein, we report the importance of assessing effects of diluents themselves on behavioral and pathologic processes in preclinical models of disease. Whether repeated administration of other commonly used formulation vehicles is similarly associated with such widespread pathology remains to be rigorously defined but is of clear preclinical value as more and 
more emphasis is placed on rigor and reproducibility in science (Landis et al., 2012). For instance, if a promising investigational agent, regardless of clinical indication, was formulated in MC and run alongside MC vehicle treatment in a preclinical model of disease, the behavioral and chemical signals of adverse effects due to intraperitoneally administered MC vehicle itself would be distinctly absent. Subsequent toxicological assessment could, however, reveal histopathology that would be falsely attributed to the investigational agent, rather than $\mathrm{MC}$, causing the agent to be potentially inappropriately withdrawn from further development. This repeated, low-dose MC administration protocol is commonly used for preclinical discovery of ASDs and other therapies; our present study should not negate the prior demonstration of efficacy of investigational agents formulated in MC on behavioral endpoints of these models. Instead, our study emphasizes that comprehensive understanding of the biologic impact of the investigational therapy and the formulation diluent should be considered when interpreting preclinical findings.

\section{Authorship Contributions}

Participated in research design: Meeker, Beckman, Treuting, Barker-Haliski.

Conducted experiments: Meeker, Beckman, Knox, Treuting, Barker-Haliski.

Contributed new reagents or analytic tools: Treuting.

Performed data analysis: Meeker, Beckman, Treuting, BarkerHaliski.

Wrote or contributed to the writing of the manuscript: Meeker, Beckman, Knox, Treuting, Barker-Haliski.

\section{References}

Abu-Hijleh MF, Habbal OA, and Moqattash ST (1995) The role of the diaphragm in lymphatic absorption from the peritoneal cavity. J Anat 186:453-467.

Albertini G, Walrave L, Demuyser T, Massie A, De Bundel D, and Smolders I (2018) $6 \mathrm{~Hz}$ corneal kindling in mice triggers neurobehavioral comorbidities accompanied by relevant changes in c-Fos immunoreactivity throughout the brain. Epilepsia 59:67-78.

Auvin S, Mazarati A, Shin D, and Sankar R (2010a) Inflammation enhances epileptogenesis in the developing rat brain. Neurobiol Dis 40:303-310.

Auvin S, Shin D, Mazarati A, and Sankar R (2010b) Inflammation induced by LPS enhances epileptogenesis in immature rat and may be partially reversed by IL1RA. Epilepsia 51 (Suppl 3):34-38

Barker-Haliski M (2019) How do we choose the appropriate animal model for antiseizure therapy development? Expert Opin Drug Discov: 1-5 [published ahead of print].

Barker-Haliski ML, Dahle EJ, Heck TD, Pruess TH, Vanegas F, Wilcox KS, and White HS (2015) Evaluating an etiologically relevant platform for therapy development for temporal lobe epilepsy: effects of carbamazepine and valproic acid on acute seizures and chronic behavioral comorbidities in the Theiler's murine encephalomyelitis virus mouse model. J Pharmacol Exp Ther 353:318-329.

Barker-Haliski ML, Johnson K, Billingsley P, Huff J, Handy LJ, Khaleel R, Lu Z, Mau MJ, Pruess TH, Rueda C, et al. (2017a) Validation of a preclinical drug screening platform for pharmacoresistant epilepsy. Neurochem Res 42:1904-1918.

Barker-Haliski ML, Löscher W, White HS, and Galanopoulou AS (2017b) Neuroinflammation in epileptogenesis: insights and translational perspectives from new models of epilepsy. Epilepsia 58 (Suppl 3):39-47.

Barker-Haliski ML, Vanegas F, Mau MJ, Underwood TK, and White HS (2016) Acute cognitive impact of antiseizure drugs in naive rodents and corneal-kindled mice. Epilepsia 57:1386-1397.

Barton ME, Klein BD, Wolf HH, and White HS (2001) Pharmacological characterization of the $6 \mathrm{~Hz}$ psychomotor seizure model of partial epilepsy. Epilepsy Res 47: $217-227$

Brooks-Kayal AR, Bath KG, Berg AT, Galanopoulou AS, Holmes GL, Jensen FE Kanner AM, O'Brien TJ, Whittemore VH, Winawer MR, et al. (2013) Issues related to symptomatic and disease-modifying treatments affecting cognitive and neuropsychiatric comorbidities of epilepsy. Epilepsia 54 (Suppl 4):44-60.

Cusick MF, Libbey JE, Patel DC, Doty DJ, and Fujinami RS (2013) Infiltrating macrophages are key to the development of seizures following virus infection. $J$ Virol 87:1849-1860.

Ehteda A, Galettis P, Chu SW, Pillai K, and Morris DL (2012) Complexation of albendazole with hydroxypropyl- $\beta$-cyclodextrin significantly improves its pharmacokinetic profile, cell cytotoxicity and antitumor efficacy in nude mice. Anticancer Res 32:3659-3666.

Fitch FW, Rowley DA, and Bye IJ (1962) Anemia produced in the rat by methylcellulose. II. Intravenous injections of methylcellulose. Arch Pathol 74:397-402.

G S, Suvarna P, Hadigal S, Kamath P, Prabhu N, Shenoy K A, and Lc P (2014) Can metabotropic glutamate receptor 7 (mGluR 7 ) be a novel target for analgesia? J Clin Diagn Res 8:HC16-HC18.
Gad SC, Cassidy CD, Aubert N, Spainhour B, and Robbe H (2006) Nonclinical vehicle use in studies by multiple routes in multiple species. Int $J$ Toxicol 25:499-521.

Hodge HC, Maynard EA, Wilt WG Jr, Blanchet HJ Jr, and Hyatt RE (1950) Chronic oral toxicity of a high gel point methylcellulose (methocel HG) in rats and dogs. $J$ Pharmacol Exp Ther 99:112-117.

Hönack D and Löscher W (1995) Kindling increases the sensitivity of rats to adverse effects of certain antiepileptic drugs. Epilepsia 36:763-771.

Hubbard JS, Chen PH, and Boyd KL (2017) Effects of repeated intraperitoneal injection of pharmaceutical-grade and nonpharmaceutical-grade corn oil in female C57BL/6j mice. J Am Assoc Lab Anim Sci 56:779-785.

Kaneko Y, Shiozawa S, Hora K, and Nakazawa K (2003) Glomerulosclerosis develops in Thy-1 nephritis under persistent accumulation of macrophages. Pathol Int 53: 507-517.

Kehne JH, Klein BD, Raeissi S, and Sharma S (2017) The National Institute of Neurological Disorders and Stroke (NINDS) Epilepsy Therapy Screening Program (ETSP). Neurochem Res 42:1894-1903.

Kilkenny C, Browne W, Cuthill IC, Emerson M, and Altman DG; National Centre for the Replacement, Refinement and Reduction of Amimals in Research (2011) Animal research: reporting in vivo experiments--the ARRIVE guidelines. J Cereb Blood Flow Metab 31:991-993.

Klitgaard H, Matagne A, and Lamberty Y (2002) Use of epileptic animals for adverse effect testing. Epilepsy Res 50:55-65.

Koneval Z, Knox KM, White HS, and Barker-Haliski M (2018) Lamotrigine-resistant corneal-kindled mice: a model of pharmacoresistant partial epilepsy for moderatethroughput drug discovery. Epilepsia 59:1245-1256.

Landis SC, Amara SG, Asadullah K, Austin CP, Blumenstein R, Bradley EW, Crystal RG, Darnell RB, Ferrante RJ, Fillit H, et al. (2012) A call for transparent reporting to optimize the predictive value of preclinical research. Nature 490:187-191.

Loewen JL, Barker-Haliski ML, Dahle EJ, White HS, and Wilcox KS (2016) Neuronal injury, gliosis, and glial proliferation in two models of temporal lobe epilepsy. $J$ Neuropathol Exp Neurol 75:366-378.

Lukas G, Brindle SD, and Greengard P (1971) The route of absorption of intraperitoneally administered compounds. J Pharmacol Exp Ther 178:562-564.

Mai SHC, Sharma N, Kwong AC, Dwivedi DJ, Khan M, Grin PM, Fox-Robichaud AE, and Liaw PC (2018) Body temperature and mouse scoring systems as surrogate markers of death in cecal ligation and puncture sepsis. Intensive Care Med Exp 6: 20.

Matagne A and Klitgaard H (1998) Validation of corneally kindled mice: a sensitive screening model for partial epilepsy in man. Epilepsy Res 31:59-71.

Palmer JG, Eichwald EJ, Cartwright GE, and Wintrobe MM (1953) The experimental production of splenomegaly, anemia and leukopenia in Albino rats. Blood 8:72-80. Patra PH, Barker-Haliski M, White HS, Whalley BJ, Glyn S, Sandhu H, Jones N, Bazelot M, Williams CM, and McNeish AJ (2019) Cannabidiol reduces seizures and associated behavioral comorbidities in a range of animal seizure and epilepsy models. Epilepsia 60:303-314.

Potschka H and Löscher W (1999) Corneal kindling in mice: behavioral and pharmacological differences to conventional kindling. Epilepsy Res 37:109-120.

Rex TS, Boyd K, Apple T, Bricker-Anthony C, Vail K, and Wallace J (2016) Effects of repeated anesthesia containing urethane on tumor formation and health scores in male C57BL/6j mice. J Am Assoc Lab Anim Sci 55:295-299.

Roth DR and Krinke GJ (1994) Occurrence of foam cells in the choroid plexus of rats injected intraperitoneally with methylcellulose. Exp Toxicol Pathol 45:413-414.

Rowley DA, Fitch FW, and Bye IJ (1962) Anemia produced in the rat by methylcellulose. I. Repeated intraperitoneal injections of methylcellulose. Arch Pathol 74: 331-339.

Rowley NM and White HS (2010) Comparative anticonvulsant efficacy in the corneal kindled mouse model of partial epilepsy: correlation with other seizure and epilepsy models. Epilepsy Res 92:163-169.

Salman H, Bessler H, Bergman M, Fibach E, and Djaldetti M (2006) Functional hypersplenism in mice induced by adoptive transfer of syngeneic spleen cells. Exp Biol Med (Maywood) 231:112-116.

Smith MD, Woodhead JH, Handy LJ, Pruess TH, Vanegas F, Grussendorf E, Grussendorf J, White K, Bulaj KK, Krumin RK, et al. (2017) Preclinical comparison of mechanistically different antiseizure, antinociceptive, and/or antidepressant drugs in a battery of rodent models of nociceptive and neuropathic pain. Neurochem Res 42:1995-2010

Srivastava AK and White HS (2013) Carbamazepine, but not valproate, displays pharmacoresistance in lamotrigine-resistant amygdala kindled rats. Epilepsy Res 104:26-34

Teoh TB (1961) The effects of methyl cellulose in rats with special reference to splenomegaly, anaemia and the problem of hypersplenism. J Pathol Bacteriol 81: $33-44$

Turner PV, Pekow C, Vasbinder MA, and Brabb T (2011) Administration of substances to laboratory animals: equipment considerations, vehicle selection, and solute preparation. J Am Assoc Lab Anim Sci 50:614-627.

Ullman-Culleré MH and Foltz CJ (1999) Body condition scoring: a rapid and accurate method for assessing health status in mice. Lab Anim Sci 49:319-323.

Vezzani A, Friedman A, and Dingledine RJ (2013) The role of inflammation in epileptogenesis. Neuropharmacology 69:16-24.

Weissman SM, Waldmann TA, Levin E, and Berlin NI (1961) An attempt to produce hypersplenism in the dog, using methylcellulose. Blood 17:632-642.

White HS and Barker-Haliski M (2016) Antiepileptic drug discovery, in The Treatment of Epilepsy (Shorvon SD, Perucca E, and Engel J Jr eds) pp 52-60, John Wiley \& Sons, Ltd, The Atrium, Southern Gate, Chichester, West Sussex, PO19 8SQ, UK.

Address correspondence to: Dr. Melissa Barker-Haliski, Department of Pharmacy, University of Washington, 1959 NE Pacific Street, Box 357630, Seattle, WA 98195. E-mail: mhaliski@uw.edu 